\title{
PENGARUH INVESTASI CSR DALAM MENINGKATKAN PROFITABILITAS DAN HARGA SAHAM PERUSAHAAN YANG TERDAFTAR DI INDEKS SRI KEHATI PERIODE 2011-2015
}

\author{
THE INFLUENCE OF CSR INVESTMENT ON IMPROVING PROFITABILITY AND STOCK PRICE OF \\ COMPANIES REGISTERED IN SRI KEHATI INDEX 2011-2015
}

\author{
Gugah Praharawati *) , I Made Adyana*), dan Fachruddin M Mangunjaya**) \\ *) Program Magister Sains Manajemen, Sekolah Pasca Sarjana Universitas Nasional \\ Jl. Harsono RM. No. 1 Ragunan, Jakarta Selatan \\ **) Program Magister Biologi, Sekolah Pasca Sarjana Universitas Nasional \\ Jl. Sawo Manila, Pejaten Ps. Minggu Jakarta 12520
}

\begin{abstract}
This research aimed to analyze the impact of corporate social responsibility (CSR) in increasing the profitability and stock price. This research used an explanatory research approach or a quantitative analysis. The sampling took thirteen companies registered in Sri Kehati Index at the period of 2011-2015. The developed model consists of three independent variables and two dependent variables. This research used the purposive sampling method. The analytical method used in this study was multiple regression analysis on annual data of 2011 to 2015 period. The results of this study indicated that the environmental CSR has no significant to the profitability (NPM), yet has a positively significant effect on stock price. In addition, economic CSR has no significant on profitability (NPM) and stock price, while social CSR has a positively significant effect on profitability (NPM) and has no significant effect on stock price. The correlation between the three CSR variables to profitability (NPM) and stock price is still relatively weak; i.e. $34.5 \%$ for profitability (NPM), and $27.3 \%$ for stock price, while the contribution of this variable to NPM is only $11.9 \%$, and $7.5 \%$ to the stock price.
\end{abstract}

Keywords: environment_CSR, economic_CSR, social CSR, NPM, and stock_price

\begin{abstract}
Abstrak: Penelitian ini bertujuan menganalisis pengaruh investasi CSR dalam meningkatkan profitabilitas dan harga saham. Studi yang digunakan dalam penelitian ini adalah explanatory research atau studi penjelasan dengan pendekatan Kuantitatif. Sampel yang digunakan adalah 13 perusahaan yang terdaftar pada indeks Sri Kehati periode 2011-2015. Model yang dikembangkan terdiri dari tiga varibel bebas dan dua variabel terikat. Metode yang dipakai dalam pengambilan sampel menggunakan metode purposive sampling. Analisis menggunakan model regresi berganda dan data tahunan periode 2011-2015. Hasil studi ini memperlihatkan bahwa CSR_lingkungan tidak berpengaruh signifikan terhadap profitabilitas(NPM), tetapi berpengaruh signifikan positif terhadap harga_saham. CSR_ekonomi tidak berpengaruh signifikan terhadap profitabilitas (NPM) dan harga_saham, sedangkan CSR_sosial berpengaruh signifikan positif terhadap profitabilitas (NPM) dan tidak berpengaruh signifikan terhadap harga_saham. Hubungan antara ketiga variabel CSR terhadap profitabilitas (NPM) dan harga_saham masih tergolong lemah yaitu $34,5 \%$ untuk profitabilitas (NPM) dan 27,3\% untuk harga_saham, Adapun untuk kontribusi variabel ini terhadap profitabilitas (NPM) hanya $11,9 \%$ dan $7,5 \%$ terhadap harga_saham.
\end{abstract}

Kata kunci: CSR_lingkungan, CSR_ekonomi, CSR_sosial, NPM, harga_saham

\footnotetext{
${ }^{1}$ Corresponding author:

Email: pgugah@gmail.com
} 


\section{PENDAHULUAN}

Sebagai upaya untuk menunju keberlanjutan dalam melakukan usaha, maka mempertimbangkan kegiatan keberlanjutan kondisi sosial dan memelihara lingkungan hidup, menjadi suatu keniscayaan. Oleh karena itu, perusahaan terus berlomba membuat program untuk menarik hati publik, salah satunya dengan memanfaatkan corporate social responsibility (CSR), juga dalam meyakinkan pemangku kepentingan (Orlitzky et al. 2011; Stuerer et al. 2005; Silveira, 2018). Pada dasarnya arah kebijakan CSR dapat dikelompokkan dalam dua katagori, pertama adalah katagori responsif dan yang kedua adalah katagori strategis. Kategori responsif merupakan sebuah langkah yang dilaksanakan oleh CSR perusahaan yang dalam aktifitasnya bersifat 'memperbaiki' dampak yang ditimbulkan oleh perusahaan, seperti permasalahan sosial/lingkungan yang ada di masyarakat. Salah satu bentuk kegiatannya adalah kegiatan filantropi, yaitu untuk kegiatan pemberdayaan terhadap masyarakat. Hal ini dapat memberikan dampaknya kepada perusahaan untuk dapat terlibat langsung didalam berbagai permasalahan yang terjadi di masyarakat, terutama di sekitar lingkungan tempat beroperasinya perusahaan.

Kegiatan lain yang bersifat strategis, adalah untuk kebijakan perusahaan pada kegiatan CSR yang dikembangkan sesuai dengan kompetensi dan kapasitas perusahaan. Hal ini merupakan langkah dalam upaya pendekatan agar seluruh kegiatan CSR perusahaan akan terintegrasi dengan baik pada fungsi operasi perusahaan, dan tidak menjadi sebuah kegiatan yang terpisah sehingga fokusnya pada permasalahan tertentu mampu memberikan dampak yang lebih signifikan dalam jangka panjang, terutama dalam keberlanjutan perusahaan (De Sausa et al. 2010; Engert et al. 2016; Martinez-Garcia et al. 2018).

Aktivitas kegiatan CSR sebagai kewajiban perseroan telah diatur didalam Pasal 74 UU No. 40 Tahun 2007 perihal perseroan terbatas, bahwa perusahaan berkomitmen untuk berperan dalam tanggungjawab sosial danlingkungan, selainituperusahaanikutberperan serta dalam pembangunan ekonomi berkelanjutan untuk meningkatkan kualitas kehidupan sosial dan lingkungan, yang dapat memberikan manfaat baik bagi perusahaan itu sendiri, ataupun masyarakat sekitarnya. Namun, sampai sekarang ini untuk pelaksanaan program CSR dibilang masih lemah. Dilihat dari sisi akuntabilitas, pelaksanaannya masih rendah, tidak transparan dan terbuka. Padahal kegiatan ini diharapkan produktif dalam upaya membantu pendapatan ekonomi, peningkatan pendidikan dan penyadaran terhadap lingkungan dan upaya pengentasan kemiskinan yang menjadi target pemerintah. Selain itu, CSR juga diharapkan dapat menunjang target pembangunan berkelanjutan atau Sustainable Development Goals (SDGs) (Behringer et al. 2016; Moon et al. 2007).

Aksi perusahaan melakukan CSR pada dasarnya merupakan wujud komitmen yang didasari pada keputusan dalam mengambil kebijakan dan tindakan dengan memperhatikan kepentingan stakeholder dan lingkungan. Selain perusahaan melakukan aktivitasnya dilandaskan pada ketentuan hukum yang berlaku (Lako, 2011), Undang-undang tentang CSR memberikan pernyataan bahwa semua perusahaan diwajibkan untuk memberikan laporan tentang pelaksanaan tanggungjawab sosial dan lingkungan di dalam annual report (laporan tahunan). Oleh sebab itu, perusahaan harus menyadari bahwa hubungan perusahaan dengan masyarakat sekitarnya saling berkaitan, sejalan dengan teori legitimasi, yaitu antara keduanya mempunyai keeratan dalam hubungan sosial sehingga antara keduanya terikat dalam suatu kontrak sosial. Dengan demikian, kegiatan yang dilakukan oleh perusahaan bukanlah bersifat sukarela (Asmeri et al. 2017).

Berdasarkan hal tersebut didalam melaksanakan CSR perusahaan selain memberikan manfaat kepada stakeholders, diharapkan perusahaan juga mendapatkan keuntungan melalui kinerja profitabilitasnya. Secara umum penelitian CSR sebelumnya juga telah dilakukan di Amerika dan Europa (Arx dan Ziegler, 2008). Sedangkan penelitian lain yang dilakukan Foroghi dan Jahromy (2015) tentang dampak profitabilitas terhadap return saham di 60 anggota Bursa Efek Teheran selama periode 2005-2012 telah menghasilkan bahwa profitabilitas berdampak pada return saham dan faktor-faktor yang dapat meningkatkan profitabilitas menjadi faktor yang penting untuk diperhatikan dalam memperoleh laba yang tinggi. Di Indonesia, penelitian CSR yang dilakukan oleh Ridho (2017) tentang pengaruh CSR terhadap kinerja dan penentu yang mempengaruhi perusahaan. Selain profitabilitas juga berpengaruh kepada tingkat akuntabilitas dan kinerja keuangan perusahaan, mengurangi risiko dan memberikan gambaran yang baik untuk perusahaan. Profitabilitas dapat juga digunakan untuk membantu analisis keuangan bagi investor dan kreditor. 
Studi CSR yang dilakukan di Indonesia dilaksanakan dalam ruang lingkup menggali bagaimana penerapan aktivitas CSR dalam perusahaan dengan melihat pengungkapannya dalam laporan tahunan seperti indikator kinerja_ekonomi, kinerja_lingkungan, dan kinerja_sosial. Pada penelitian Caesari (2015) menunjukkan CSR berpengaruh signifikan terhadap kinerja perusahaan, dan pada penelitian Dewi (2015) CSR berpengaruh terhadap nilai ROA (return on asset) dan ROE (return on equity).

Hasil studi return saham perusahaan yang terdaftar di indeks Sri_Kehati periode 2009-2012 yang dilakukan oleh Anggraini (2014) memperlihatkan hasil adanya pergerakan return saham yang mengalami fluktuasi selama periode tersebut, return saham mengalami penurunan dari tahun 2009-2011 dan penurunan return terendah pada tahun 2011, yaitu sebesar $-0,08$, kemudian kembali meningkat pada tahun 2012, yaitu sebesar 0,07. Pergerakan tersebut memperlihatkan keadaan pasar, yaitu saat keadaan pasar sedang baik dan juga para investor optimis jika berinvestasi di pasar modal akan menguntungkan, maka harga saham akan mengalami peningkatan. Penting bagi investor yang akan berinvestasi di pasar modal, nilai harga saham menjadi bahan pertimbangan. Indeks berfungsi sebagai indikator tren pasar. Artinya, pergerakan indeks menggambarkan kondisi pasar sedang menurun atau meningkat (Aditya, 2018)

Latar belakang dapat dijadikan alasan untuk penulis melakukan studi penelitian dengan tujuan menjelaskan pengaruh investasi CSR dalam meningkatkan profitabilitas dan harga_saham pada perusahaan yang terdaftar di indeks Sri_Kehati periode 2011-2015. Agar topik yang diteliti dapat dikaji secara luas dan mendalam maka ruang lingkup studi ini dibatasi hanya kepada 3 variabel bebas, yaitu CSR_ekonomi, CSR lingkungan dan CSR_sosial dan 2 variabel terikat profitabilitas (NPM) dan harga_saham.

\section{METODE PENELITIAN}

Jenis data yang digunakan dalam studi ini adalah data sekunder. Pengambilan data berasal dari laporan tahunan, laporan keuangan, laporan keberlanjutan dan laporan CSR dari masing-masing perusahaan pada periode tahun 2011-2015. Data diambil dari BEI (Bursa Efek Indonesia). Objek penelitian adalah profitabilitas yang diproksikan dari nilai NPM (Net Profit Margin) dan harga saham perusahaan yang terdaftar di indeks Sri_Kehati periode tahun 2011-2015 sebagai variabel terikat. Variabel tersebut dipengaruhi oleh CSR ekonomi, CSR_lingkungan dan CSR_sosial sebagai variabel bebas.

Cara yang dipakai dalam studi ini adalah dengan menggunakan teknik dokumentasi dari bermacam dokumen dan berkaitan dengan variabel yang sedang diteliti. Cara yang digunakan dalam pengambilan data menggunakan metode purposive sampling (sebuah cara didalam mengambil data berdasarkan pertimbanganpertimbangan atau memakai kriteria khusus atau ketentuan yang menjadi bahan pertimbangan). Berdasarkan pada ketentuan tersebut perusahan yang terpilih ada 13 dan akan dijadikan sampel, kriterianya sebagai berikut: Difokuskan pada saham perusahaan yang terdaftar di indeks Sri_Kehati secara konsisten masuk dalam daftar BEI (Bursa Efek indonesia) selama tahun 2011-2015; Perusahaannya tidak pernah diberhentikan perdagangannya oleh Bursa Efek Indonesia; Setiap bulan saham perusahaan aktif diperdagangkan selama tahun 2011-2015; Selama periode penelitian setiap bulan terdapat laporan perdagangan saham emiten; Memiliki laporan tahunan selama periode penelitian.

Dalam pengungkapan CSR ada 79 item pengungkapan dan telah disesuaikan dengan kondisi yang ada di Indonesia sesuai dengan peraturan yang berlaku. Versi yang banyak digunakan di Indonesia selama periode penelitian yaitu tahun 2011-2015 adalah GRI standart (Anggraini, 2014; GRI, 2015). Pengungkapan 79 item tersebut dibagi menjadi 3 indikator besar yaitu sebagai berikut: Kinerja ekonomi (indikator ini memiliki 9 item); Kinerja lingkungan (indikator ini memiliki 30 item); Bidang sosial (indikator ini memiliki 40 item).

Pengolahan data dengan menggunakan analisis statistik inferensia merupakan bagian statistika yang bertujuan untuk memperoleh informasi yang diperoleh dari sampel, metode ini membahas cara menganalisis data serta mengambil kesimpulan mengenai keseluruhan data yang berkaitan dengan parameter atau pengujian hipotesis. Sebagai alat bantu menggunakan SPSS22 dengan analisis regresi berganda dan menggunakan angka unstandarisasi. Model Regresi dapat dirumuskan sebagai berikut:

$$
\begin{gathered}
\mathrm{Y} 1=\alpha+\beta_{1} \mathrm{X}_{1}+\beta_{2} \mathrm{X}_{2}+\beta_{3} \mathrm{X}_{3}+\mathrm{e} \\
\mathrm{Y} 2=\alpha+\beta_{1} \mathrm{X}_{1}+\beta_{2} \mathrm{X}_{2}+\beta_{3} \mathrm{X}_{3}+\mathrm{e}
\end{gathered}
$$


Dimana: $\mathrm{Y}_{1}\left(\right.$ profitabilitas(NPM)); $\mathrm{Y}_{2}$ (harga_saham); $\alpha$ (konstanta); $\beta(1-3)$ (koefisien regresi); X1(CSR lingkungan); X2 (CSR_ekonomi); X3 (CSR_sosial); e (Error term).

Hipotesis yang digunakan merupakan eksplanasi asosiatif simetris untuk melihat apakah ada hubungan atau pengaruh antara ketiga variabel CSR dengan profitabilitas (NPM) dan harga_saham, dengan kerangka pemikiran yang diuraikan pada Gambar 1 . Sehingga dapat dibuat hipotesis yang digunakan dalam studi ini sebagai berikut:

H1: CSR_ekonomi berpengaruh signifikan positif terhadap profitabilitas (NPM)

H2: CSR_ekonomi berpengaruh signifikan positif terhadap harga_saham

H3: CSR_lingkungan berpengaruh signifikan positif terhadap profitabilitas (NPM)

H4: CSR_lingkungan berpengaruh signifikan positif terhadap harga_saham

H5: CSR_sosial berpengaruh signifikan positif terhadap profitabilitas (NPM)

H6: CSR_sosial berpengaruh signifikan positif terhadap harga_saham

\section{HASIL}

Hasil penelitian dan perhitungan CSR pada Tabel 1 menggambarkan nilai rata rata CSR_perusahaan yang diungkapkan selama periode 2011-2015. Hasil CSR_ ekonomi berkisar 0,27\%-0,38\% yaitu pada perusahaan Indofood Sukses Makmur Tbk dan perusahaan Tambang Batubara Bukit Asam (Persero) Tbk memiliki pengungkapan nilai CSR_ekonomi berkisar 0,27\% dan angka ini lebih kecil jika dibandingkan dengan pengungkapan CSR_ekonomi dari perusahaan lainnya yang memiliki nilai CSR $0,33-0,38 \%$. Kegiatan CSR dalam bidang ekonomi dari masing-masing perusahaan berbeda-beda tergantung besarnya laba perusahaan. Semakin tinggi laba perusahaan semakin banyak sebuah perusahaan melakukan kegiatan CSR. Agar kegiatan CSR ekonomi terus berlanjut maka CSR perusahaan dapat terlibat dan mendampingi pemerintah daerah (Pemda) untuk melakukan monitoring pelaksanaan kerja sama pada sektor terkait untuk memastikan kegiatan tersebut berkontribusi dalam pencapaian 100\%-0\%$100 \%$ yang tercantum dalam Rencana Program Jangka Menengah Nasional (RPJMN) 2015-2019, yaitu target $100 \%$ akses air .

Pengungkapan CSR_lingkungan perusahaan memiliki nilai $0,31 \%-0,45 \%$. Sedangkan pengungkapan CSR sosial perusahaan memiliki nilai 0,56\%-0,74\%. Dari hasil ini dapat menggambarkan bahwa CSR_lingkungan dan CSR_sosial mempunyai keterkaitan yang cukup kuat dengan perusahasaan. Menurut yayasan Kehati emiten yang terdaftar pada indeks Sri_Kehati adalah perusahaan yang lolos dalam mekanisme PT BEI dan telah menggunakan prinsi-prinsip keberlanjutan, financial dan tata laksana atau tata kelola serta kepedulian terhadap lingkungan hidup dengan baik. Mekanisme tinjau ulang dan pembaruan dilakukan melalui kuesioner oleh emiten serta data lain yang relevan dengan tahapan bisnis inti, aspek keuangan dan aspek dasar seperti lingkungan dan sosial. Perusahaan yang menjalankan pengungkapan CSR berarti dapat mendukung program keberlanjutan. Selain itu bila investor akan berinvestasi di instrumen berbasis indeks Sri Kehati secara langsung mendukung kelestarian keanekaragaman hayati.

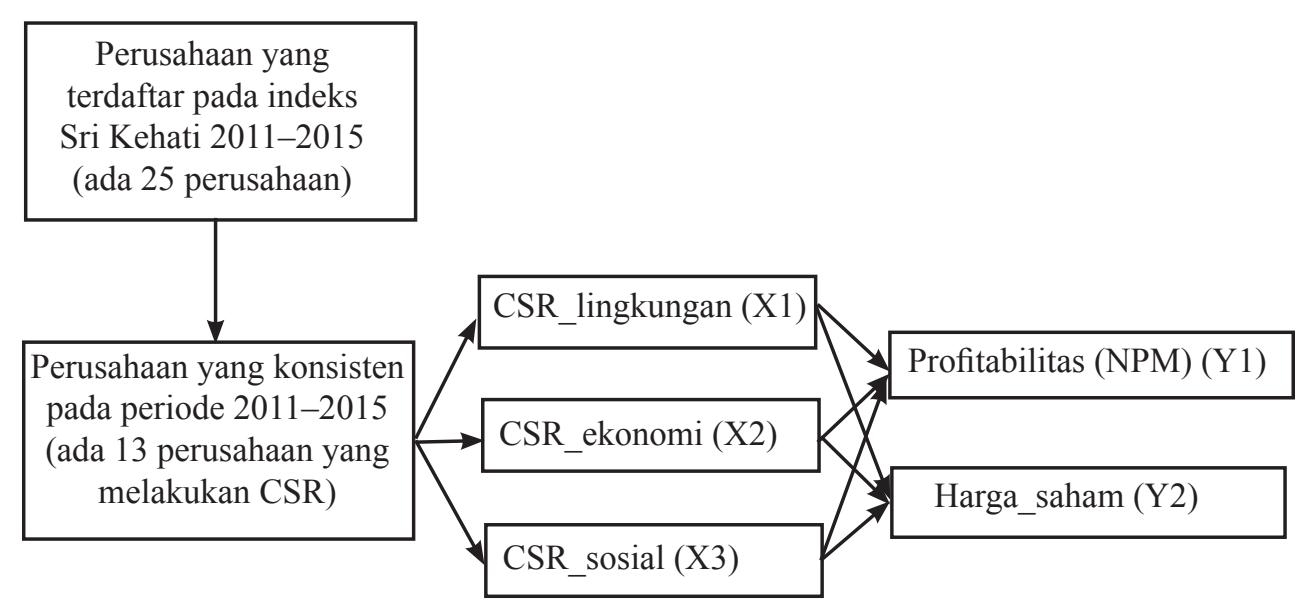

Gambar 1. Kerangka pemikiran penelitian 


\section{Analisis Data dan Pengujian Hipotesis}

Uji asumsi klasik digunakan untuk mengalisis bahwa multikolinearitas, autokorelasi, dan heteroskedastisitas tidak terdapat dalam model yang digunakan dan data yang dihasilkan terdistribusi normal. Hasil uji asumsi klasik dapat dijabarkan sebagai berikut:

\section{Uji Normalitas}

Uji Normalitas adalah sebuah uji yang dilakukan dengan tujuan untuk menilai sebaran data pada sebuah kelompok data atau variabel, apakah sebaran data tersebut berdistribusi normal ataukah tidak. Konsep dasar dari uji normalitas Kolmogorov Smirnov adalah dengan membandingkan distribusi data (yang akan diuji normalitasnya)dengandistribusinormalbaku. Distribusi normal baku adalah data yang telah ditransformasikan ke dalam bentuk Z-Score dan diasumsikan normal. Jadi, sebenarnya uji Kolmogorov Smirnov adalah uji beda antara data yang diuji normalitasnya dengan data normal baku. Pada pengujian ini digunakan statistik nonparametrik (Tabel 2)

Seperti pada uji beda biasa, jika signifikansi di bawah 0,05 berarti terdapat perbedaan yang signifikan, dan jika signifikansi di atas 0,05 maka tidak terjadi perbedaan yang signifikan. Penerapan pada uji Kolmogorov Smirnov adalah bahwa jika signifikansi dibawah 0,05 berarti data yang akan diuji mempunyai perbedaan yang signifikan dengan data normal baku, berarti data tersebut tidak normal. Pada Tabel 3 hasil asymp.Sig. (2-taled) $0,053>0,05$. Artinya, data berdistribusi normal. Pada Gambar 3 terlihat data berbentuk normal dan simetris.

Tabel 1. Nilai Rata-rata CSR_Perusahaan yang terdaftar di indeks Sri_Kehati 2011-2015

\begin{tabular}{lccc}
\hline Perusahaan & CSR_ekonomi & CSR_lingkungan & CSR_sosial \\
\hline Astra Agro Lestari tbk & 0,328 & 0,406 & 0,669 \\
Adaro Energy Tbk & 0,340 & 0,428 & 0,686 \\
Astra Internasional Tbk & 0,378 & 0,416 & 0,721 \\
Indofood Sukses Makmur Tbk & 0,276 & 0,335 & 0,563 \\
Kalbe Farma Tbk & 0,346 & 0,399 & 0,666 \\
PP London Sumatera Indonesia Tbk & 0,348 & 0,410 & 0,690 \\
Perusahaan Gas Negara Tbk & 0,346 & 0,399 & 0,666 \\
Tambang Batubara Bukit Asam (Persero) Tbk & 0,268 & 0,314 & 0,591 \\
Semen Indonesia (Persero) Tbk & 0,346 & 0,399 & 0,666 \\
Timah Tbk & 0,356 & 0,411 & 0,688 \\
Telekomunikasi Indonesia Tbk & 0,378 & 0,446 & 0,737 \\
United Traktors Tbk & 0,378 & 0,446 & 0,737 \\
Uniliver Indonesia Tbk & 0,356 & 0,411 & 0,688 \\
\hline
\end{tabular}

Tabel 2. Hasil Uji Kolmogorov Smirnov

\begin{tabular}{|c|c|c|}
\hline & & $\begin{array}{l}\text { Uns tandardized } \\
\text { Residual }\end{array}$ \\
\hline \multicolumn{2}{|l|}{$\mathbf{N}$} & 65 \\
\hline \multirow{2}{*}{ Normal Parameters ${ }^{a, b}$} & Mean & 0 \\
\hline & Std. Deviation & 8,19395529 \\
\hline \multirow{3}{*}{$\begin{array}{l}\text { Most Extreme } \\
\text { Differences }\end{array}$} & Absolute & 0,109 \\
\hline & Positive & 0,109 \\
\hline & Negative & $-0,049$ \\
\hline \multirow{2}{*}{\multicolumn{2}{|c|}{$\begin{array}{l}\text { Test Statistic } \\
\text { Asymp. Sig. (2-tailed) }\end{array}$}} & 0,109 \\
\hline & & $.053^{c}$ \\
\hline
\end{tabular}




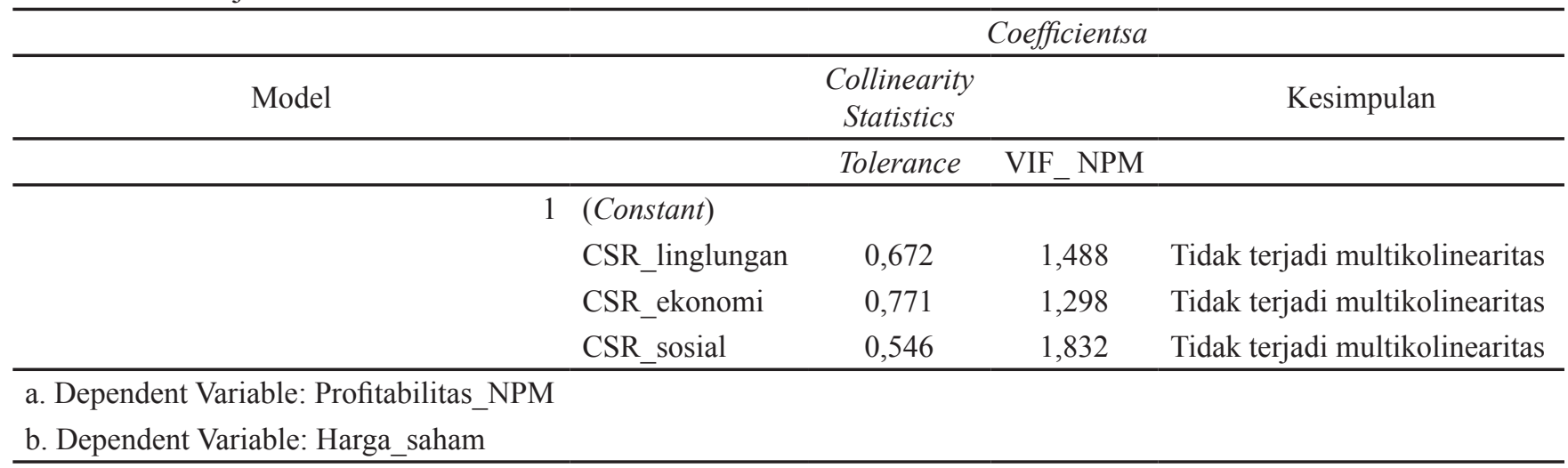

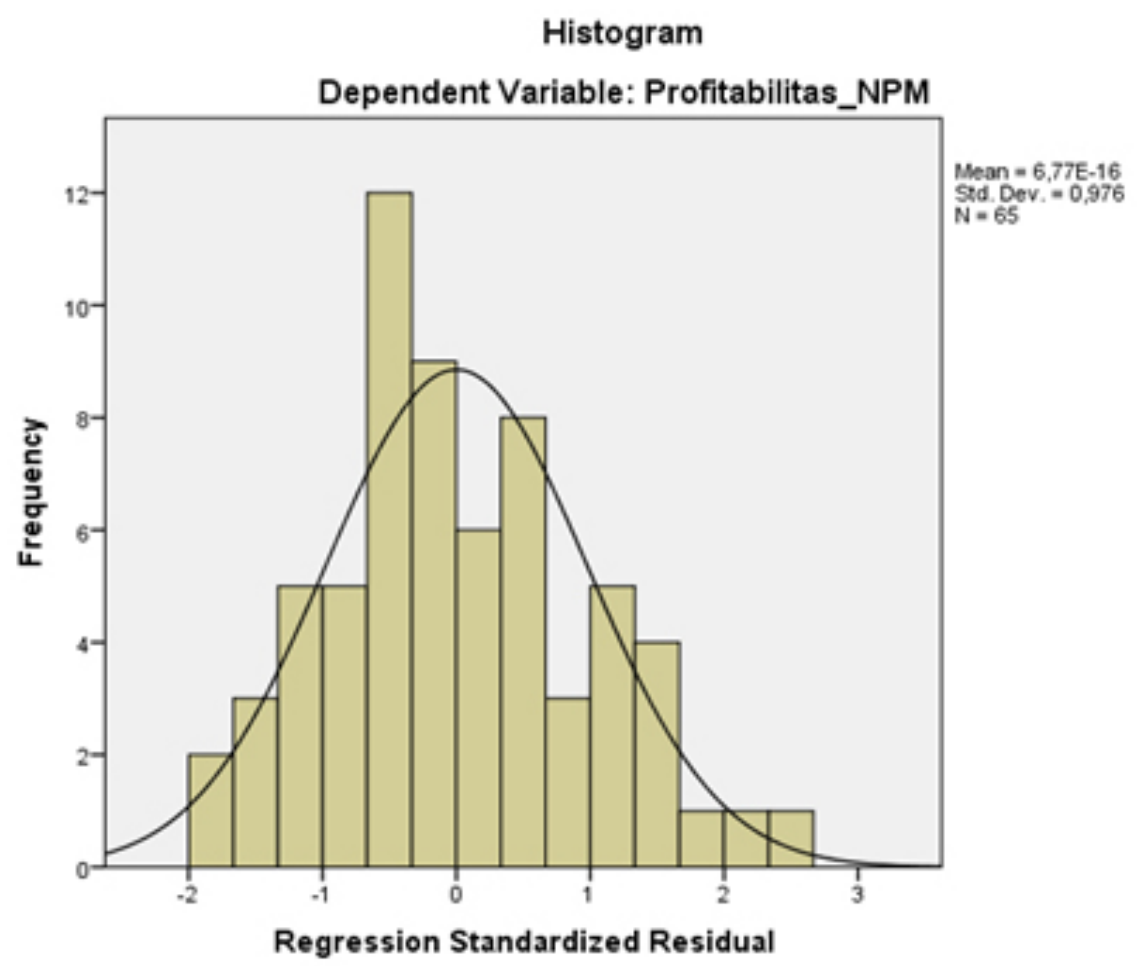

Gambar 3. Data berdistribusi normal

Uji Multikolinearitas

Uji multikolinearitas adalah uji yang dilakukan untuk memastikan apakah di dalam sebuah model regresi ada interkorelasi atau kolinearitas antar variabel bebas. Interkorelasi adalah hubungan yang linear atau hubungan yang kuat antara satu variabel bebas atau variabel prediktor dengan variabel prediktor lainnya didalam sebuah model regresi. Interkorelasi itu dapat dilihat dengan nilai koefisien korelasi antara variabel bebas, nilai VIF (variance inflation factor) dan tolerance, nilai eigenvalue dan condition index, serta nilai standar error koefisien beta atau koefisien regresi parsial. Dari hasil uji diatas nilai VIF dari hasil regresi parsial di bawah nilai 10 dan nilai tolerance lebih dari 0,01 maka dapat disimpulkan tidak terjadi multikolinieritas.
Uji Autokorelasi

Uji autokorelasi bertujuan menguji apakah model dalam suatu model regresi linear ada korelasi antara kesalahan pengganggu pada periode $t$ dengan kesalahan periode sebelumnya $\mathrm{t}-1$. Jika terjadi korelasi berarti ada masalah autokorelasi. Model yang baik sebaiknya bebas autokorelasi. Hasil uji ini dilakukan dengan uji durbin Watson dapat disajikan pada Tabel 4.

Hasil uji durbin Watson pada model 1, pengaruh CSR terhadap profitabilitas (NPM) menunjukkan nilai durbin Watson( $\mathrm{dW}$ ) berada diantara nilai dU hingga 4-dU yaitu 1,941 yang terletak antara dU 1,659 > dW 1,941<4-dU 2,341. Artinya, asumsi tidak terjadinya autokorelasi. Hasil uji pada model 2, pengaruh CSR terhadap harga 
saham nilai durbin Watson (dW) berada diantara dU hingga 4dU yaitu dU 1,659 > dW 2,194< 4dU 2,341 asumsi tidak terjadi autokorelasi. Dengan demikian, model 1 dan model 2 tidak terjadi autokorelasi maka dapat dikatakan model 1 dan 2 yang baik.

\section{Uji Heteroskedastisitas}

Uji ini bertujuan mengetahui apakah dalam sebuah model regresi terjadi ketidaksamaan varians dari residual antara satu pengamatan dengan pengamatan yang lain atau disebut dengan heteroskedastisitas. Hasil uji ini dapat ditunjukkan pada Tabel 5. Hasil uji pada model 1 dan model 2 menunjukkan nilai korelasi $>0,05$ yang berarti dapat diasumsikan nonheteroskedastisitas sehingga dapat dikatakan model ini baik.

\section{Pengaruh CSR terhadap Profitabilitas Perusahaan}

Hasil pengujian dengan regresi berganda ini dilakukan untuk mengetahui seberapa besar pengaruh variabel CSR _lingkungan, CSR_ekonomi dan CSR_sosial terhadap profitabilitas dan harga_saham (Tabel6). Hasil perhitungan pada model 1 merupakan bahasan untuk menjawab hipotesis $\mathrm{H} 1, \mathrm{H} 2$ dan $\mathrm{H} 3$, yaitu pengaruh CSR terhadap profitabilitas (NPM) perusahaan secara keseluruhan menggambarkan CSR_lingkungan dan CSR_ekonomi hasilnya tidak berpengaruh signifikan terhadap profitabilitas (NPM) yang berarti hipotesis H1 dan H2 ditolak, sedangkan CSR_sosial berpengaruh signifikan positif terhadap profitabilitas (NPM) perusahaan dengan nilai nyata $0.009<0,05$, atau secara parsial hasil $\mathrm{t}$ hitung 2,681 $>\mathrm{t}$ tabel 1,994, yang berarti hipotesis H3 diterima. Koefisien regresi variabel CSR lingkungan (X) sebesar -11,909. Artinya, jika variabel independen lain nilainya tetap dan CSR_lingkungan mengalami kenaikkan 1\% maka profitabilitas (NPM) (Y) akan mengalami penurunan sebesar Rp11,909. Koefisien bernilai negatif artinya terjadi hubungan negatif antara CSR_lingkungan dengan profitabilitas, semakin naik nilai CSR_lingkungan maka semakin turun profitabilitas. Koifisien regresi variabel CSR ekonomi (X) sebesar -154,444. Artinya, jika variabel independen lain nilainya tetap dan CSR_ekonomi mengalami kenaikkan 1\%, maka profitabilitas (NPM) (Y) akan mengalami penurunan sebesar Rp 154,444. Koefisien bernilai negatif artinya terjadi hubungan negatif antara CSR_ekonomi dengan profitabilitas, semakin naik nilai CSR_ekonomi maka semakin turun profitabilitas. Sedangkan pada CSR_sosial (X) sebesar 52,812 . Artinya, jika variabel independen lain nilainya tetap dan CSR_sosial mengalami kenaikkan 1\%, maka profitabilitas (NPM) (Y) akan mengalami kenaikan sebesar Rp 52,812. Koefisien bernilai positif artinya terjadi hubungan positif antara CSR_sosial dengan profitabilitas, semakin naik nilai CSR_sosial maka semakin naik profitabilitas. Dalam hal ini profitabilitas perusahaan dapat disimpulkan mempunyai pengaruh yang diakibatkan oleh investasi CSR disektor sosial. Pada dasarnya kegiatan sosial yang dilakukan melalui CSR, akan berdampak secara langsung maupun secara tidak langsung. Keuntungan langsung pada perusahaan dipandang dari beberapa sudut, misalnya peningkatan ekonomi masyarakat yang diberdayakan, peningkatan pengetahuan masyarakat dan kesadaran masyarakat terhadap kegiatan CSR yang telah dilakukan oleh perusahan tersebut kepada mereka.

Tabel 4. Hasil uji durbin Watson (dW)

\begin{tabular}{lccccc}
\hline Model & $\mathrm{R}$ & R Square & Adjusted R Square & Std. Error of the Estimate & durbin-Watson \\
\hline 1 &, $345 \mathrm{a}$ &, 119 &, 075 & 8,393028 & 1,941 \\
\hline \begin{tabular}{l} 
a. Predictors: (Constant), CSR_sosial, CSR_ekonomi, CSR_lingkungan \\
\hline b. Dependent Variable: Profitabilitas(NPM)
\end{tabular} & & & \\
\hline 2 &, $231 \mathrm{a}$ &, 053 &, 007 & 1058339,34458 & 2,194 \\
\hline a. Predictors: (Constant), CSR_sosial, CSR_ekonomi, CSR_lingkungan & & \\
\hline
\end{tabular}


Tabel 5. Hasil Uji Heteroskedastisitas

\begin{tabular}{|c|c|c|c|c|c|c|}
\hline \multirow{2}{*}{\multicolumn{2}{|c|}{ Model }} & \multicolumn{2}{|c|}{ Unstandardized Coefficients } & \multirow{2}{*}{$\frac{\text { Standardized Coefficients }}{\text { Beta }}$} & \multirow{2}{*}{$\mathrm{t}$} & \multirow{2}{*}{ Sig. } \\
\hline & & B & Std. Error & & & \\
\hline \multicolumn{7}{|c|}{ Dependent Variable: RES_5 } \\
\hline \multirow[t]{4}{*}{1} & (Constant) & $4,864 \mathrm{E}-15$ & 6,517 & & ,000 & 1,000 \\
\hline & CSR_lingkungan & 0,000 & 16,002 & 0,000 & 0,000 & 1,000 \\
\hline & CSR_ekonomi & 0,000 & 84,841 & 0,000 & 0,000 & 1,000 \\
\hline & CSR_sosial & 0,000 & 19,697 & 0,000 & 0,000 & 1,000 \\
\hline \multicolumn{7}{|c|}{ Dependent Variable: RES_9 } \\
\hline \multirow[t]{4}{*}{2} & (Constant) & $2,071 \mathrm{E}-12$ & 6579,210 & &, 000 & 1,000 \\
\hline & CSR_lingkungan & 0,000 & 16153,385 & 0,000 & 0,000 & 1,000 \\
\hline & CSR_ekonomi & 0,000 & 85646,198 & 0,000 & 0,000 & 1,000 \\
\hline & CSR_sosial & 0,000 & 19883,411 & 0,000 & 0,000 & 1,000 \\
\hline
\end{tabular}

Tabel 6. Coefficients Pengaruh CSR terhadap Profitabilitas (NPM) dan Harga_saham

\begin{tabular}{|c|c|c|c|c|c|c|c|c|}
\hline & \multirow[t]{2}{*}{ Model } & \multicolumn{2}{|c|}{ Unstandardized Coefficients } & \multirow{2}{*}{$\begin{array}{c}\begin{array}{c}\text { Standardized } \\
\text { Coefficients }\end{array} \\
\text { Beta }\end{array}$} & \multirow[t]{2}{*}{$\mathrm{t}$} & \multirow[t]{2}{*}{ Sig. } & \multirow[t]{2}{*}{ Hipotesis } & \multirow[t]{2}{*}{ Kesimpulan } \\
\hline & & B & Std. Error & & & & & \\
\hline \multicolumn{9}{|c|}{ Dependent Variable: Profitabilitas_NPM } \\
\hline \multirow[t]{4}{*}{1} & (Constant) & 17,84 & 6,517 & & 2,737 & 0,008 & & Nyata \\
\hline & CSR_lingkungan & $-11,909$ & 16,003 & $-0,109$ & $-0,744$ & 0,46 & H1 & Tidak nyata \\
\hline & CSR_ekonomi & $-154,444$ & 84,847 & $-0,249$ & $-1,82$ & 0,074 & $\mathrm{H} 2$ & Tidak nyata \\
\hline & CSR_sosial & 52,812 & 19,697 & 0,436 & 2,681 & 0,009 & $\mathrm{H} 3$ & Nyata \\
\hline \multicolumn{9}{|c|}{ Dependent Variable: Harga_saham } \\
\hline \multirow[t]{4}{*}{2} & (Constant) & 10998,305 & $657,92,1$ & & 1,672 & 0,1 & & Tidak nyata \\
\hline & CSR_lingkungan & 33895,478 & 16153,4 & 0,315 & 2,098 & 0,04 & $\mathrm{H} 4$ & Nyata \\
\hline & CSR_ekonomi & $-27082,303$ & 85646,2 & $-0,044$ & $-0,316$ & 0,753 & H5 & Tidak nyata \\
\hline & CSR_sosial & $-27981,318$ & 19883,4 & $-0,234$ & $-1,407$ & 0,164 & H6 & Tidak nyata \\
\hline
\end{tabular}

Hasil uji menghasilkan persamaan model 1 sebagai berikut:

$$
\mathrm{Y} 1=\alpha+\beta_{1} \mathrm{X}_{1}+\beta_{2} \mathrm{X}_{2}+\beta_{3} \mathrm{X}_{3}+\mathrm{e}
$$

Profitabilitas $(\mathrm{NPM})=17,84$ - 11,909CSR_lingkungan $-154,444$ CSR_ekonomi $+52,812$ CSR_sosial

\section{Pengaruh CSR terhadap Harga_saham}

Hasil perhitungan pada model 2 merupakan bahasan dari hipotesis $\mathrm{H} 4, \mathrm{H} 5$ dan $\mathrm{H} 6$ dari pengaruh CSR terhadap harga_saham perusahaan. secara keseluruhan menggambarkan bahwa CSR_lingkungan berpengaruh signifikan positif terhadap harga_saham dengan nilai $0,040<0,05$, secara parsial hasil $t$ hitung 2,098 $>\mathrm{t}$ tabel 1,996 yang berarti hipotesis (H4) diterima. Sedangkan hasil dari pengujian CSR_ekonomi dan CSR_sosial tidak berpengaruh signifikan terhadap harga_saham yang berarti H5 dan H6 ditolak. Koefisien regresi variabel CSR_lingkungan (X) sebesar 33895,478; artinya jika variabel independen lain nilainya tetap dan CSR_lingkungan mengalami kenaikkan 1\%, maka harga_saham (Y) akan mengalami peningkatan sebesar Rp33.895,478. Koefisien bernilai positif artinya terjadi hubunganantaraCSR_lingkungandenganharga_saham, semakin naik nilai CSR_lingkungan maka semakin tinggi harga_saham. Koifisien regresi variabel CSR ekonomi (X) sebesar -27.082,303; artinya jika variabel independen lain nilainya tetap dan CSR_ekonomi mengalami kenaikkan 1\% maka harga_saham (Y) akan mengalami penurunan sebesar Rp27.082,303. Koefisien bernilai negatif artinya terjadi hubungan negatif antara CSR_ekonomi dengan harga_saham, semakin naik nilai CSR_ekonomi maka semakin turun harga_saham. Pada CSR_sosial (X) sebesar -27.981,318; artinya jika variabel independen lain nilainya tetap dan CSR_sosial mengalami kenaikkan 1\% maka harga_saham (Y) akan mengalami penurunan sebesar Rp27.981,318. Koefisien bernilai negatif artinya terjadi hubungan negatif antara CSR_sosial dengan harga_saham, semakin naik nilai CSR_sosial maka semakin turun harga_saham. 
Harga saham akan bergerak positif apabila diketahui ada kinerja lingkungan yang baik terutama dalam upaya menyesuaikan pada target global maupun pemerintah. Dari 30 indikator lingkungan dalam mengungkap kinerja CSR menurut GRI (2016), yang diuji pada penelitian ini terdapat 16 indikator yang mengarah pada indikator global, salah satunya yang mencakup keanekaragaman hayati serta emisi, kebocoran dan limbah. Kesadaran publik termasuk pemegang saham yang perduli terhadap isu iklim dan pemanasan global serta kepunahan spesies, bisa jadi mendorong kekuatan untuk berinvestasi pada saham-saham SRI Kehati. Sebaliknya perofitabilitas bisa menurun apabila terdapat kinerja yang mengganggu pada kepedulian isuisu global di atas, misalnya isu yang kontraproduktif dimana perusahaan berkontribusi pada emisi gas-gas rumah kaca akibat kebakaran hutan. Kinerja perusahaan dapat dibaca melalui kegiatan CSR mereka, apakah mereka merugikan lingkungan atau negatif terhadap lingkungan atau positif terhadap kondisi lingkungan yang pada ujungnya akan berpengaruh terhadap harga saham perusahaan.

Hasil uji menghasilkan persamaan model 2 sebagai berikut:

$$
\mathrm{Y}_{2}=\alpha+\beta_{1} \mathrm{X}_{1}+\beta_{2} \mathrm{X}_{2}+\beta_{3} \mathrm{X}_{3}+\mathrm{e}
$$

Harga_saham $=10998,305+33895,478$ CSR lingkungan - 27082,303CSR_ekonomi -27981,318CSR_sosial.
Hasil pengujian ANOVA atau pengujian F hitung Tabel 7, maka ketiga indikator CSR bila digabungkan secara bersama-sama maka hasilnya memperlihatkan bahwa pada model 1; pengaruh CSR terhadap profitabilitas (NPM) hasilnya signifikan jika pengambilan keputusan pada $\alpha=10 \%$, yaitu $0,051<0,1$ dan pada model 2 ; pengaruh CSR terhadap harga_saham tidak memiliki pengaruh nyata baik pada pengambilan keputusan pada tingkat $\alpha=5 \%$ ataupun pada $\alpha=10 \%$, yaitu 0,182 $>0,1$. Artinya, tidak ada perbedaan makna rerata pada semua kelompok. Ada beberapa faktor yang dapat menyebabkan kemungkinan ini adanya gangguan multikolinier antar variabel bebas atau adanya kesalahan konfigurasi model sehingga meskipun secara parsial hasil uji t signifikan, akan tetapi secara simultan tidak menggambarkan variabel terikat dalam model. Sehingga ada perbaikan model 2 agar perusahaan tetap dapat mengambil keputusan dalam berinvestasi dalam CSR_lingkungan pada $\alpha=10 \%$, yaitu dengan tidak mengikutkan variabel CSR_ekonomi sebagai variabel bebas terhadap harga_saham sehingga didapat nilai $\alpha=$ $0,091<0,1$. Perubahan terlihat pada Tabel 8 dan Tabel 9 serta pada Gambar 3 (perubahan persamaan regresi).

Persamaan Regresi pada Model 2

$$
\mathrm{Y}_{2}=\alpha+\beta_{1} \mathrm{X}_{1}+\beta_{3} \mathrm{X}_{3}+\mathrm{e}
$$

Harga_saham $=9453,963+34297,635$ CSR lingkungan - 30742,254CSR_sosial

Tabel 7. ANOVA

\begin{tabular}{lllclcc}
\hline Model & & Sum of Squares & df & Mean Square & F & Sig. \\
\hline 1 & Regression & 578,687 & 3 & 192,896 & 2,738 & $0,051^{\mathrm{b}}$ \\
& Residual & 4297,018 & 61 & 70,443 & & \\
& Total & 4875,705 & 64 & & 1,673 & $0,182^{\mathrm{b}}$ \\
\hline 2 & Regression & 360309946,890 & 3 & 120103315,630 & & \\
& Residual & 4378919027,725 & 61 & 71785557,832 & & \\
& Total & 4739228974,615 & 64 & & & \\
\hline
\end{tabular}

a. Dependent Variable: Profitabilitas_NPM dan harga_saham

b. Predictors: (Constant), CSR_sosial, CSR_ekonomi, CSR_linglungan

Tabel 8. ANOVA Model 2

\begin{tabular}{lllclcc}
\hline Model & & Sum of Squares & df & Mean Square & F & Sig. \\
\hline 1 & Regression & 353132134,733 & 2 & 176566067,367 & 2,496 & $0,091^{\mathrm{b}}$ \\
& Residual & 4386096839,882 & 62 & 70743497,417 & & \\
& Total & 4739228974,615 & 64 & & & \\
\hline
\end{tabular}

a. Dependent Variable: Harga_saham

b. Predictors: (Constant), CSR_sosial, CSR_lingkungan 
Tabel 9.Coefficients Model 2

\begin{tabular}{|c|c|c|c|c|c|c|}
\hline \multirow{2}{*}{\multicolumn{2}{|c|}{ Model }} & \multicolumn{2}{|c|}{ Unstandardized Coefficients } & \multirow{2}{*}{$\begin{array}{l}\text { Standardized Coefficients } \\
\text { Beta }\end{array}$} & \multirow{2}{*}{$\mathrm{t}$} & \multirow{2}{*}{ Sig. } \\
\hline & & $\mathrm{B}$ & Std. Error & & & \\
\hline \multirow[t]{3}{*}{1} & (Constant) & 9453,963 & 4376,243 & & 2,160 &, 035 \\
\hline & CSR_lingkungan & 34297,635 & 15985,935 & ,319 & 2,145 & ,036 \\
\hline & CSR_sosial & $-30742,254$ & 17733,644 &,- 258 & $-1,734$ & ,088 \\
\hline
\end{tabular}

a. Dependent Variable: Harga_saham

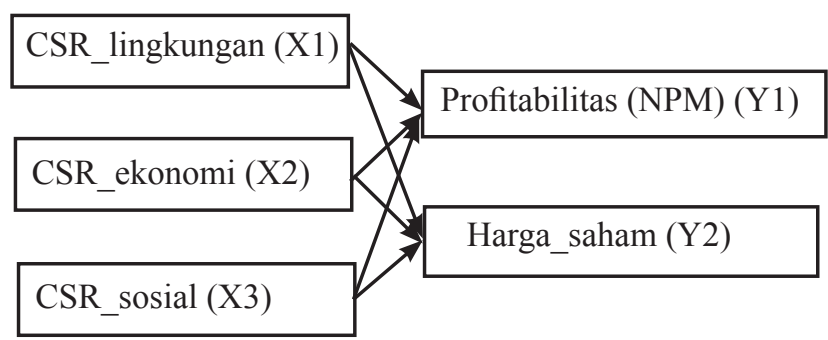

Gambar 3. Struktur Model 1 dan 2

Pada analisis ganda (R) dihasilkan Model Summary, menggambarkan hasil hubungan antara variabel terikat dengan variabel bebas. Pada nilai $\mathrm{R}$ sebesar 0.345 atau $34,5 \%$ untuk profitabilitas(NPM) dan 0.275 atau $27,5 \%$ untuk harga_saham. Menurut Sugiono (2010) interpretasi koefisien korelasi tersebut tergolong lemah, karena bila korelasi mendekati angka 1 berarti sangat kuat. Sedangkan untuk kontribusi variabel ini terhadap profitabilitas(NPM) hanya $11,9 \%$ dan 7,5\% terhadap harga_saham. Perbaikan model memberikan hasil kepada perusahaan untuk tetap dapat mengambil keputusan pada $\alpha=10 \%$. Penelitian ini berbeda dengan hasil penelitian Hidayansyah et al. (2015) tentang Pengaruh Pengungkapan CSR terhadap harga saham yang tidak signifikan pada perusahaan sektor properti di Bursa Efek Indonesia. Oleh karenanya, para investor dalam hal ini sangat penting untuk melihat pergerakan harga_saham, yaitu untuk mengetahui fluktuasi harga saham perusahaan yang akan diinvestasi, terutama faktor faktor internal ataupun eksternal perusahaan (Erviana dan Lako, 2018)

Corporate Social Responsibility atau yang dikenal dengan CSR, merupakan kewajiban suatu perusahaan kepada komunitas lokal dimana perusahaan itu beroperasi. Tanggungjawab ini telah menjadi ketetapan yang disusun dalam Undang-Undang (UU RI No.40 tahun 2007 pasal 74) yaitu tentang tanggungjawab lingkungan dan sosial. Kegiatan yang dilakukan oleh CSR diharapkan mempunyai hubungan yang integral dengan masyarakat dimana perusahaan ini berada dan beroperasi. Selanjutnya masyarakatpun dapat menerima sebagai bagian dari perusahaan dalam melakukan kegiatan sosialnya. Tetapi karena masih banyak halangan dalam berbagai persoalan, akhirnya perusahaan hanya bergerak dalam pendanaan saja, dan masyarakat merasa perusahaan belum sepenuhnya bertanggungjawab dengan dampak yang ditimbulkan seperti lingkungan yang tercemar oleh sampah dan limbah pabrik, udara yang kotor oleh limbah asap dan air yang tercemar dan masih banyak lagi masalah yang lain.

Pada situasi dan kondisi seperti ini LSM mempunyai peranan yang penting dan diperlukan. Selain itu pemda sebaiknya juga dapat mensosialisasikan investasi asing. Dan LSM (Lembaga Swadaya Masyarakat) yang ada, dapat berperan sebagai mediasi kepada masyarakat. Hal ini perlu dilakukan untuk menjaga hubungan baik antara keduanya yaitu perusahaan dan masyarakat, sehingga ketika ada peristiwa tragis yang ditimbulkan akibat operasi perusahaan dapat diatasi secara bijak. Pada umumnya tanggapan yang positip dapat berkembang menjadi kegiatan CSR.

Dalam menjalankan kegiatan CSR, maka faktor ekternal juga mempunyai peranan penting yang membuat kegiatan CSR yang dilakukan oleh perusahaan dapat bertahan dalam persaingan dunia usaha. Sedangkan secara internal perusahaan akan melihat bahwa CSR berpeluang untuk mendapatkan keunggulan bersaing (resposibility is opportunity). Para pengamat ada yang berpendapat bahwa faktor internal inilah yang dapat mendorong kegiatan CSR berperan penting untuk jangka panjang.

Penggambaran umum yang dapat dilihat adalah bila perusahaan tidak memperhatikan aspek sosial dan lingkungan, tetapi hanya mementingkan aspek benefid dalam financial untuk jangka pendek saja. Maka dampak akibat aspek sosial akan menimbulkan protes masyarakat yang berakibat kepada operasi perusahaan seperti adanya demonstrasi atau boikot. Begitu juga 
dari aspek lingkungan berakibat kepada reputasi perusahaan dimata investor dalam maupun luar negeri yang enggan membiayai proyek baru. Oleh sebab itu selaras dengan prinsip triple bottom line yang mengarah kepada kepentingan umum jangka panjang maka investasi CSR sangatlah berharga.

Sehingga pada akhirnya, ketika masyarakat yang dibantu telah mandiri dan membuahkan hasil dan tidak lagi tergantung kepada program program yang disumbangkan, Maka dampaknya menjadi positip bagi masyarakat itu sendiri atau bagi perusahan untuk jangka panjang. Sedangkan pada program-program yang berkaitan dengan lingkungan, sebaiknya memiliki semangat atau berorientasi kepada pembangunan berkelanjutan (sustainable development), dan tidak hanya untuk jangka pendek atau sesaat.

\section{Implikasi Manajerial}

Hasil penelitian ditemukan beberapa bukti empiris yang didasarkan kepada temuan penelitian dan dapat dianjurkan sebagai implikasi manajerial dalam skala perioritas yang dapat diberikan sebagai masukan kepada perusahaan yang terdaftar pada indeks Sri_Kehati bahwa jika berinvestasi dalam CSR_lingkungan maka dapat berpengaruh terhadap harga_saham dan CSR sosial akan berpengaruh terhadap profitabilitas, hal ini menggambarkan bahwa CSR yang dilakukan oleh perusahaan dapat meningkatkan atau menaikkan profit dan harga_saham perusahaan. Sehingga disarankan agar Corporate Social Responsibility (CSR) tetap dilakukan oleh perusahaan karena dampak yang baik akan dirasakan oleh masyarakat bukan saja sekarang tetapi untuk jangka panjang.

\section{KESIMPULAN DAN SARAN}

\section{Kesimpulan}

Hasil studi ini dapat disimpulkan bahwa 1) CSR lingkungan tidak berpengaruh signifikan terhadap profitabilitas (NPM), 2) CSR_ekonomi tidak berpengaruh signifikan terhadap profitabilitas (NPM), 3) CSR_sosial berpengaruh signifikan positif terhadap profitabilitas, 4) CSR_lingkungan berpengaruh signifikan positif terhadap harga_saham dan 5) CSR sosial tidak berpengaruh signifikan terhadap harga saham. Hubungan antara ketiga variabel CSR terhadap profitabilitas (NPM) dan harga saham masih tergolong lemah. 34,5\% untuk profitabilitas (NPM) dan 27,3\% untuk harga_saham, Sedangkan untuk kontribusi variabel ini terhadap profitabilitas (NPM) hanya $11,9 \%$ dan $7,5 \%$ terhadap harga_saham. Kesimpulan ini mengindikasikan jika investor akan berinvestasi dalam saham perusahaan yang terdaftar di Indeks Sri_kehati sebaiknya merujuk pada CSR_sosial untuk meningkatkan profitabilatas (NPM) perusahaan dan merujuk pada CSR_lingkungan untuk meningkatkan harga_saham sehingga dapat menilai prospek keberlanjutan perusahaan dimasa yang akan datang

\section{Saran}

Hasil studi ini memberikan gambaran bahwa investasi CSR merupakan investasi jangka panjang. Bila investor ingin berinvestasi disaham perusahaan yang terdaftar di Indeks Sri_Kehati sebaiknya dapat memperhitungkan beberapa hal, yaitu apabila ingin berinvestasi untuk meningkatkan profitabilitas perusahaan, sebaiknya melihat nilai laba bersih perusahaan atau nilai NPM perusahaan, akan tetapi apabila ingin berinvestasi dibidang lingkungan maka dapat berinvestasi dengan melihat harga saham perusahaan. Walaupun hubungan antara CSR dengan profitabilitas perusahaan dan harga saham masih lemah, tetapi indikator ini dapat dijadikan acuan untuk investasi jangka panjang.

\section{DAFTAR PUSTAKA}

Anggraini D. 2014. Pengaruh corporate social responsibility, profitabilitas dan risiko sistematik terhadap return saham indeks Sri Kehati [Skripsi]. Jakarta: Sarjana Fakultas Ekonomi Universitas Nasional.

Asmeri R, Alvionita T, Gunardi A. 2017. CSR disclosures in the mining industry: empirical evidence from listed mining firms in Indonesia. Indonesian Journal of Sustainability Accounting and Management 1(1): 16-22. https://doi. org/10.28992/ijsam.v1i1.23.

Behringer K, Szegedi K. 2016. The role of CSR in achieving sustainable development - theoretical approach. European Scientific Journal 12 (22): 10-25. https://doi.org/10.19044/esj.2016. v12n22p10.

Caesari AP. 2015. Pengaruh tata kelola perusahaan dan tanggungjawab sosial perusahaan terhadap kinerja keuangan pada perusahaan indeks 
Kompas 100 [Tesis]. Bogor: Institut Pertanian Bogor.

De Sausa FJM, Wanderley LSO, Gómez CP, Farache F. 2010. Strategic corporate social responsibility management for competitive advantage. Braziliah Adminitstation Review (BAR), Curitiba 7(3):294-309. https://doi.org/10.1590/S180776922010000300006 .

Dewi WA. 2015. Hubungan corporate social responsibility dengan kinerja $\mathrm{ke} \mathrm{u}$ a $\mathrm{ng}$ a pada perusahaan sektor pertanian dan pertambangan di bursa efek indonesia [Tesis]. Bogor: Institut Pertanian Bogor.

Engert S, Rauter R, Baumgartner RJ. 2016. Exploring the integration of corporate sustainability into strategic management: a literature review. Journal of Cleaner Production 112(4): 2833-2850. https://doi.org/10.1016/j.jclepro.2015.08.031.

Erviana CPW, Lako A. 2018 Faktor-faktor yang mempengaruhi kinerja harga saham dengan csr sebagai variabel pemoderasi. Jurnal Akuntansi Bisnis 16(2)185-208. https://doi.org/10.24167/ jab.v16i2.1697.

Foroghi D, Jahromy SME. 2015. Impact of profitabilitas on stock returns based on the price, return and differenced modelsin tehran stock exchange. International Journal of Applied Business and Economic Research 13(2): 955-970.

[GRI] Global Reporting Initiative. 2015. Environment. https://www.globalreporting.org/standards/gristandards-download-center [6 Januari 2017].

Hidayansyah PF, Hubeis M, IrwantoAK. 2015.Pengaruh pengungkapan corporate social responsibility terhadap kinerja keuangan dan harga saham pada sektor properti di bursa efek Indonesia. Jurnal Manajemen dan Organisasi 6(1): 74-89. https:// doi.org/10.29244/jmo.v6i1.12195.

Lako A. 2011. Dekonstruksi CSR dan Reformasi Paradigma Bisnis \& Akuntansi. Jakarta: Erlangga.
Martínez-Garcia E, Sorribes J, Celma D. 2018. Sustainable Development through CSR in human resource management practices: the effects of the economic crisis on job quality. Corporate Social Responsibility and Environmental Management 25: 441-456. https://doi.org/10.1002/csr.1471.

Moon J. 2007. The contribution of corporate social responsibility to sustainable development. Sustainable Development 15(5): 296-306. https://doi.org/10.1002/sd.346.

Orlitzky M, Donald S, Waldman DA. 2011. Strategic corporate social responsibility and environmental sustainability. Business \& Society 50(1): 6-27. https://doi.org/10.1177/0007650310394323

Ridho TK. 2016. The influence of CSR onperformance and its determinants in listed companies in Indonesia. Actual Problems of Economics. Scientific Economic Journal 10 (184): 259-268.

Silveira ML, Petrini M. 2018. Sustainable development and corporate social responsibility: a bibliometric analysis of international scientific production. Gestão \& Produção 25(1):56-67. http://dx.doi. org/10.1590/0104-530x3173-16

Steurer R et al. 2005. Corporations, stakeholders and sustainabledevelopment:atheoreticalexploration of business-society relations. Journal of Bisnis Ethic 61: 263. https://doi.org/10.1007/s10551005-7054-0

Sugiono 2010. Metode Penelitian Bisnis: Pendekatan Kuantitatif, Kualitatif dan $R \& D$. Bandung: Alfabeta.

Sutrisno 2013. Manajemen Keuangan Teori Konsep \& Aplikasi. Yogyakarta: Ekonisia Fakultas Ekonomi UII.

Urs von Arx, Andreas Ziegler, 2008. The Effect of CSR on Stock Performance: New Evidence for the USA and Europe. CCRS Working Paper Series. Working paper No.04.08ETH, Zurich, Switzerland. https://doi.org/10.2139/ ssrn. 1102528 . 